\title{
Reactor Subsystem Simulation for Nuclear Hybrid Energy Systems
}

\author{
J. Michael Doster \\ Alan Rominger \\ Shannon Bragg-Sitton
}

September 2012

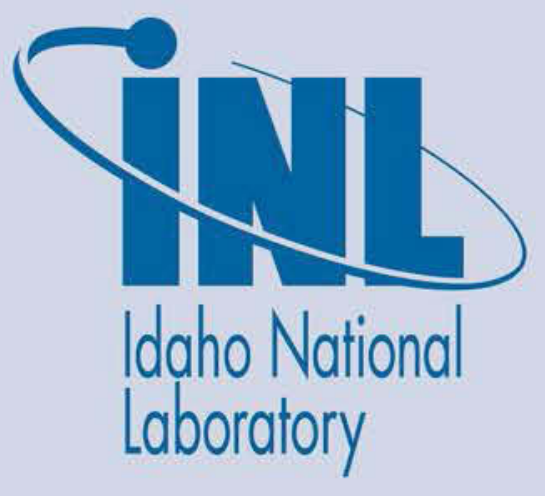

The INL is a U.S. Department of Energy National Laboratory operated by Battelle Energy Alliance 


\section{DISCLAIMER}

This information was prepared as an account of work sponsored by an agency of the U.S. Government. Neither the U.S. Government nor any agency thereof, nor any of their employees, makes any warranty, expressed or implied, or assumes any legal liability or responsibility for the accuracy, completeness, or usefulness, of any information, apparatus, product, or process disclosed, or represents that its use would not infringe privately owned rights. References herein to any specific commercial product, process, or service by trade name, trade mark, manufacturer, or otherwise, does not necessarily constitute or imply its endorsement, recommendation, or favoring by the U.S. Government or any agency thereof. The views and opinions of authors expressed herein do not necessarily state or reflect those of the U.S. Government or any agency thereof. 


\title{
Reactor Subsystem Simulation for Nuclear Hybrid Energy Systems
}

\author{
J. Michael Doster \\ Alan Rominger \\ North Carolina State University \\ Shannon Bragg-Sitton \\ Idaho National Laboratory
}

September 2012

Idaho National Laboratory Idaho Falls, Idaho 83415

http://www.inl.gov

Prepared for the

U.S. Department of Energy

Office of Nuclear Energy

Under DOE Idaho Operations Office

Contract DE-AC07-05ID14517 



\section{EXECUTIVE SUMMARY}

Nuclear Hybrid Energy Systems (NHES) could be a key part of the solution to achieving energy security, may provide reliable power availability even with increasing renewable energy penetration into the power grid, and may allow repurposing excess electricity in times of low demand. Incorporating a fission-based power source in a multi-output system (electricity and process heat) can offer significant advantages over carbon-based production sources, such as coal or natural gas, including reduction in atmospheric carbon emissions. In an integrated multi-output system, thermal energy from the nuclear reactor subsystem can be diverted to industrial applications in times of low electricity demand. High temperature, high quality heat from advanced reactor designs might be used for hydrogen production or synthetic fuel production (coal-to-liquid or natural gas-to-liquid processes). Low temperature heat from advanced reactor designs or the current and future fleet of light water reactors (LWRs) might be applied to desalination processes or be stored for later use in low temperature ammonia or hydrocarbon-based thermal cycles.

The NHES research team is currently developing a dynamic simulation of an integrated hybrid energy system. A detailed simulation of proposed NHES architectures will allow initial computational demonstration of a tightly coupled NHES to identify key reactor subsystem requirements, identify candidate reactor technologies for a hybrid system, and identify key challenges to operation of the coupled system. This work will provide a baseline for later coupling of design-specific reactor models through industry collaboration. The modeling capability addressed in this report focuses on the reactor subsystem simulation.

Many computational tools and methods are available for modeling a nuclear reactor, power conversion systems and associated process applications. One method is to develop a single program capable of modeling the entire system. Another is to combine two or more existing computer programs, each modeling a portion of the system for which it is validated, where the programs exchange information to compute the solution. The former method requires a lengthy development and verification and validation process. The latter method leverages industry standard software to reduce development and funding requirements.

Preliminary system models have been developed by Idaho National Laboratory researchers and are currently being enhanced to assess integrated system performance given multiple sources (e.g., nuclear + wind) and multiple applications (i.e., electricity + process heat). Initial efforts to integrate a Fortran-based simulation of a small modular reactor (SMR) with the balance of plant model have been completed in FY12. This initial effort takes advantage of an existing SMR model developed at North Carolina State University to provide initial integrated system simulation for a relatively low cost. The SMR subsystem simulation details are discussed in this report. 


\section{CONTENTS}

EXECUTIVE SUMMARY iii

ACRONYMS vii

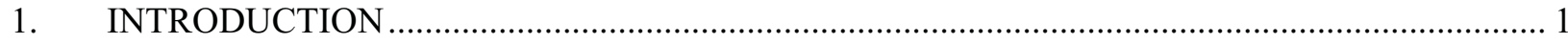

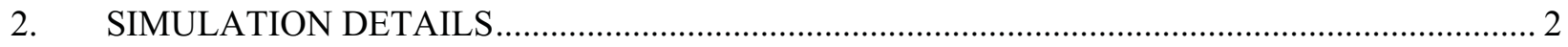

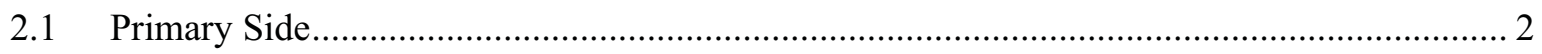

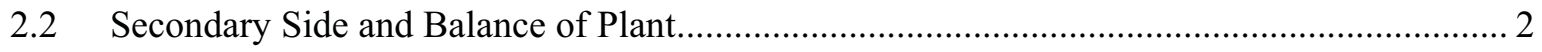

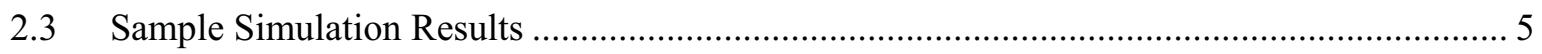

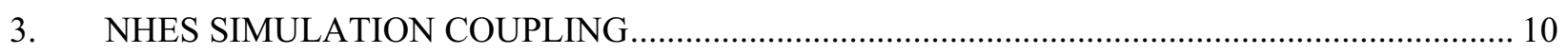

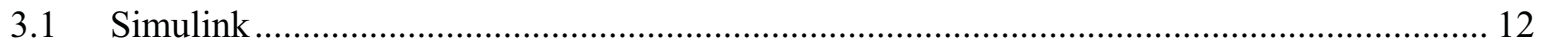

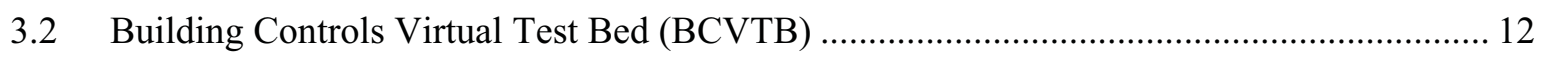

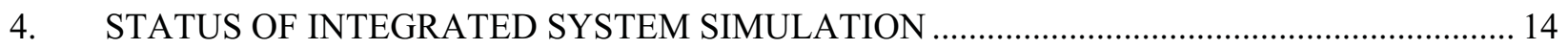

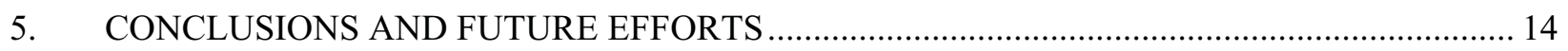

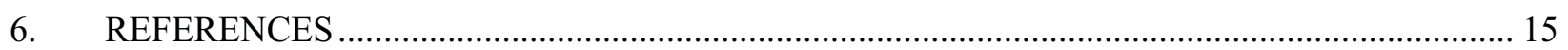

\section{FIGURES}

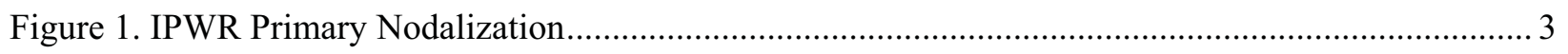

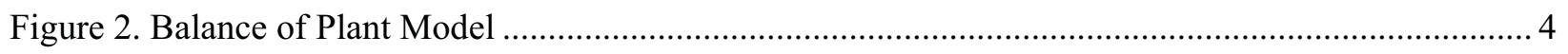

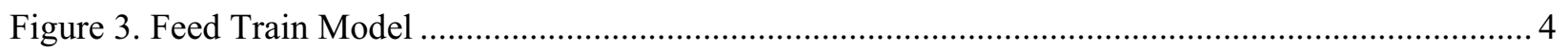

Figure 4. Turbine Output for 10\% Step Reduction in Load at Time Zero ................................................. 5

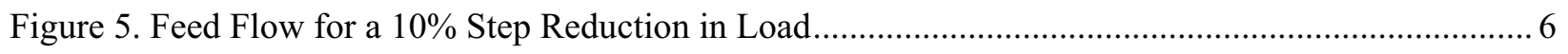

Figure 6. Reactor Thermal Output and Peak Centerline Temperature for 10\% Step Reduction ................. 6

Figure 7. Primary System Pressure and Minimum DNB Ratio for 10\% Step Reduction in Load................ 7

Figure 8. Average Primary Coolant Temperature and Pressurizer Level for 10\% Step Reduction

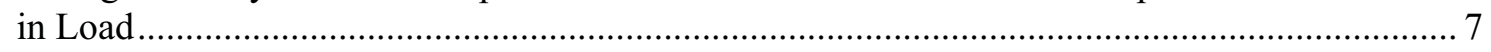

Figure 9. NHES Turbine Output for 10\% Step Reduction in Load ....................................................... 8

Figure 10. NHES Feed Flow for a 10\% Step Reduction in Load ............................................................ 8

Figure 11. NHES Reactor Thermal Output and Peak Centerline Temperature for 10\% Step

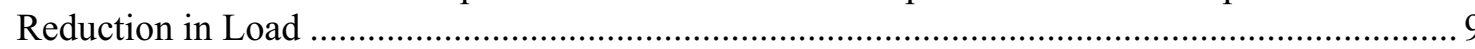

Figure 12. NHES Primary System Pressure and Minimum DNB Ratio for 10\% Step Reduction in Load.

Figure 13. NHES Average Primary Coolant Temperature and Pressurizer Level for 10\% Step Reduction in Load 
Figure 14. NHES Illustration Showing Reactor Subsystem Coupling to the Balance of Plant Simulation at the Primary Boiler...

Figure 15. Two-body Co-simulation Example in BCVTV …............................................................ 13

Figure 16. Custom Fortran Block Properties Simulation within the Example........................................... 13 


\section{ACRONYMS}

BCVTB Building Controls Virtual Test Bed

DNB Departure from Nuclear Boiling

DOE Department of Energy

INL Idaho National Laboratory

IPWR Integral Pressurized Water Reactor

LOCA Loss Of Coolant Accidents

LWR Light Water Reactor

MWe MegaWatt thermal

MWt MegaWatt electric

NHES Nuclear Hybrid Energy System

OTSG Once Through Steam Generator

PWR Pressurized Water Reactor

SMR Small Modular Reactor 


\section{Reactor Subsystem Simulation for Nuclear Hybrid Energy Systems}

\section{INTRODUCTION}

The accurate prediction of plant behavior during normal and off normal conditions requires accurate thermal-hydraulic models, as well as provisions for the simulation of auxiliary systems, mechanical components, and control functions. While these capabilities exist in varying degrees in large reactor safety codes, these codes were developed primarily for the simulation of loss of coolant and other design basis accidents where normal control functions may be assumed to be inactive or to operate in a way that makes the limiting responses of the plant more severe. As such, these codes are not optimized for the development and testing of control systems over the continuous full operating range. Codes of this type also generally require a long learning time and the source code is difficult, if not impossible, to modify.

In this work, the emphasis is on the simulation of plant response and control over the full range of operating conditions. Functionally, the plant simulation should execute quickly, require minimal up-front effort by the user, be easily modified, and allow for ease in the integration and testing of new control strategies and components. The models should allow the simulation of both the physical attributes of the system, as well as the responses of the sensors employed to measure various attributes that are observable, including uncertainties in these measurements.

NC State University has demonstrated experience in developing high fidelity, full plant simulators for predicting the dynamic response of pressurized water reactors during normal and off-normal operational conditions. Plant simulators have been developed for both conventional Pressurized Water Reactors with recirculating U-Tube steam generators, as well as integral reactor systems (IPWRs) with helical steam generators as represented by the IRIS, NuScale and the SMART reactor designs. The IPWR simulator includes a model of the pressurizer, reactor core including a six delayed neutron group kinetics model, a decay heat model and a hot channel/DNB model, a model of the primary flow loop and a model of the secondary side including the steam generators and balance of plant. The simulator is capable of describing either forced flow, or natural circulation systems such as the NuScale power module. In the current IPWR simulator, the steam generators are assumed to be helical coils, where the secondary fluid flows on the tube side of the heat exchanger. Detailed models have been developed to describe the dynamics of steam generators of this design. Modifications to allow for more traditional Once Through Steam Generator (OTSG) designs such as those incorporated in the B\&W mPower reactor can be easily implemented. The model also includes balance of plant, instrumentation and control systems, and plant protection systems including the normal spectrum of reactor trips and engineered safety features. Options are available to degrade sensor signals for flow, level, pressure, etc. as the result of noise and drift, in addition to failing the sensor all together. Additional sensor models can be easily added. The simulator models also provide ease of access to correlations for heat transfer, pressure loss, void fraction, etc.

In previous work, an IRIS specific model was developed for the IPWR simulator. IRIS is a 1000 MWt / 335 MWe plant, approximately twice the output of the B\&W mPower reactor destin, and three times the output of Korean SMART reactor design. In the current implementation, the existing IRIS model was downsized to represent a generic $500 \mathrm{MWt} / 158 \mathrm{MWe}$ IPWR with operating characteristics of interest to hybrid energy systems. 


\section{SIMULATION DETAILS}

A high fidelity model incorporating a reactor, power conversion system, and local electrical grid with sufficient detail for controls engineering has been developed at NCSU for preliminary investigation of SMRs as a dynamic stability aid in small electrical grid applications (Rominger and Doster 2010). The dynamic system code is written in Fortran and will run on any platform that has a compatible Fortran compiler. The existing Fortran code can also be linked to Matlab and Simulink for integration with INL system models.

\subsection{Primary Side}

The current IPWR simulator assumes the primary side fluid remains subcooled, i.e. two phase flow on the primary side is not considered except in the pressurizer. Integrated, loop momentum balances are used to determine time dependent flow rates. Time dependent mass and energy distributions are obtained by discretizing the mass and energy equations which are then solved for a user specified primary side nodalization. Twenty six nodes are considered for computing the primary side fluid temperature distribution and the time dependent flow equations allow for the simulation of both forced (pumped) and natural circulation flows. Specification of system geometry is sufficiently general that a number of existing IPWR designs can be readily modeled. The reactor coolant pump model allows for a user specified pump performance curve and pump inertia to allow simulation of reactor coolant pump coast down. In the power range, reactor power is determined through a six delayed group point kinetics model, with rod position controlled through a user specified $T_{\text {ave }}$ program. Reactivity feedbacks include fuel and moderator temperature, where fuel temperature is determined by solution of the time dependent heat conduction equation. Decay heat is computed using an eleven group decay heat model, which allows the prediction of decay heat rates for arbitrary power histories. Figure 1 illustrates the current primary side nodalization. While not implemented in the present model, the nodalization allows for designation of an asymmetric secondary loop if future simulation needs require it.

\subsection{Secondary Side and Balance of Plant}

Secondary Plant models are typical of current Light Water Reactor designs, and consist of the main steam lines, turbine/generator and the condensate/feed system. Models are also provided for steam dump and turbine by-pass systems, main steam safety valves and steam and feed isolation systems. The balance of plant model is illustrated in Figure 2 below. In this diagram, PSG refers to steam pressure, PHDR to the steam header pressure, ADV refers to Atmospheric Dump Valves, MSIV to Main Steam Isolation Valves, and TCV to Turbine Control Valves. A simple turbine model had been incorporated to allow electrical demand to be specified as a boundary condition and the feed control model reflects that typical of plants with OTSG designs. The turbine control valves operate to meet the steam demand while maintaining a constant pressure in the steam generators. The turbine bypass valves are currently assumed to operate only in the pressure control mode, but can be easily adapted to implement operation under load rejection. 


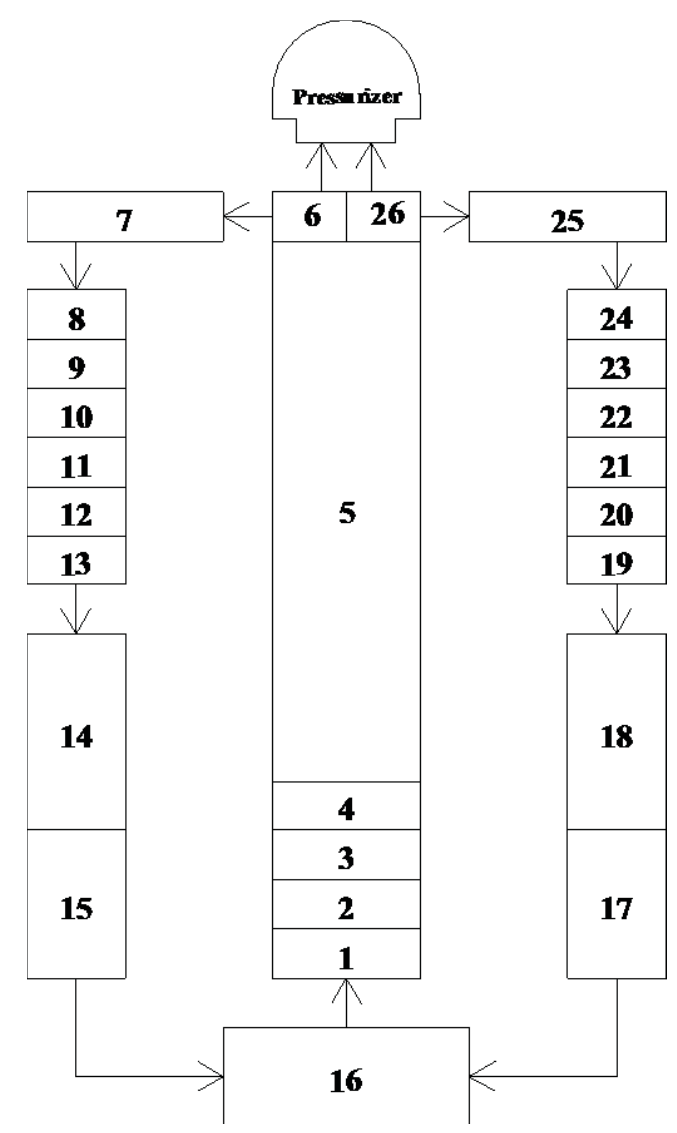

\begin{tabular}{|c|c|}
\hline Nodes & Description \\
\hline $1-4$ & Reactor Core \\
\hline 5 & Riser \\
\hline 6,26 & RCP Inlet Plenum \\
\hline 7,25 & RCP Nodes \\
\hline $8-13,19-24$ & Steam Generator \\
\hline $14-15,17-18$ & Downcomer \\
\hline 16 & Lower Plenum \\
\hline
\end{tabular}

Figure 1. IPWR Primary Nodalization

Feed control in the power range is based upon electrical demand, similar to control strategies employed in B\&W Once Through Steam Generators. The current feed train model is illustrated in Figure 3. Feed heaters are not currently modeled. Instead, feed temperature is assumed to be a function of steam demand (power level). A more comprehensive feed train model is currently under development. The hot well, condensate and feed pumps are described by user input pump performance curves. The hot well and condensate pumps are fixed speed. The feed pumps are assumed to be variable speed, with the speed controller based on maintaining a constant $\Delta \mathrm{P}$ from the feed manifold to the steam generators. 


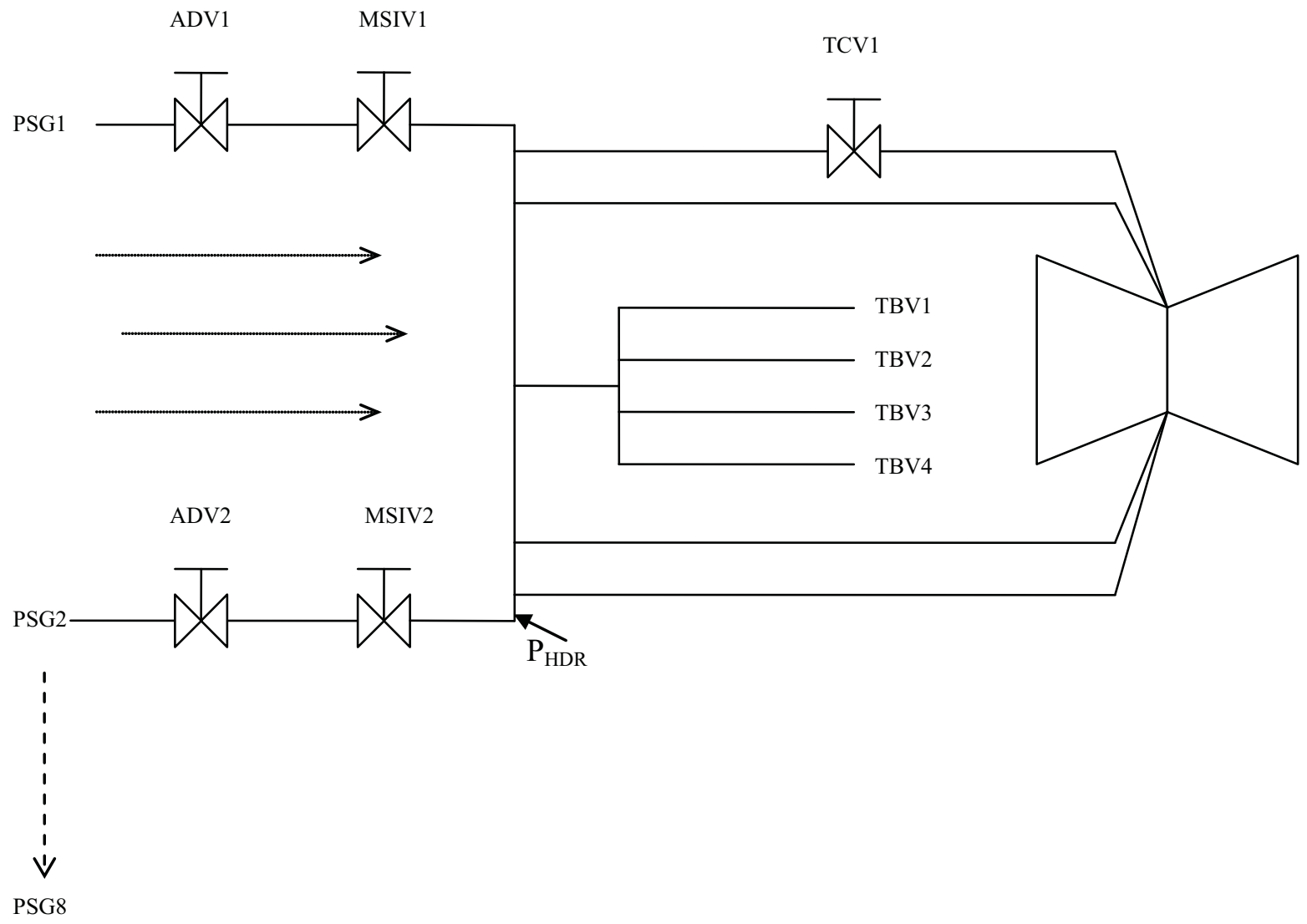

Figure 2. Balance of Plant Model

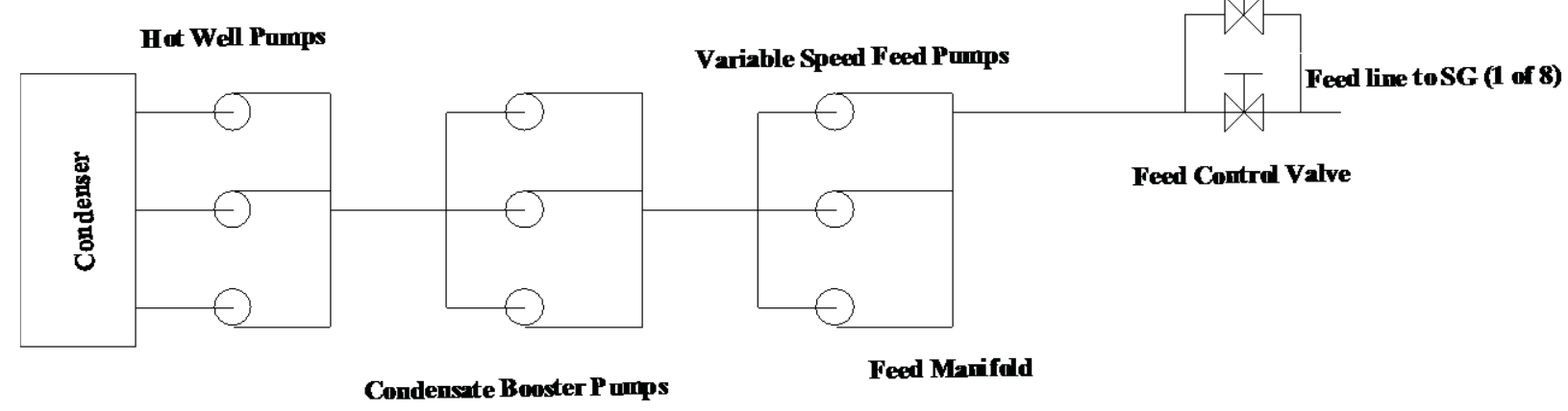

Figure 3. Feed Train Model

While the independent reactor simulation program includes the balance of plant models described here, the final integrated NHES simulation will utilize the INL-developed balance of plant models, with code coupling accomplished at the interface between the primary and secondary side of the steam generator. The secondary side of the Fortran-based reactor model is included here to provide boundary conditions for validation of the model and to illustrate capabilities of the simulation that could be useful in future work. 


\subsection{Sample Simulation Results}

The reactor simulator is capable of describing normal power maneuvers, as well as a number of upset conditions and Sensor failures. Figures $4-8$ illustrate a 10\% step reduction in load from $100 \%$ to $90 \%$ at time zero for the IRIS plant (initial load: $335 \mathrm{MWe}$ ). Of particular interest is the response of the secondary side to the load reduction. As opposed to Pressurized Water Reactors which operate with recirculating U-Tube steam generators, in the Once-Through design the turbine control valves modulate to hold steam pressure at its setpoint. Feed demand is effectively proportional to the turbine load signal. As a result, feed demand responds instantly to the step change in load and then is "shimmed" to ensure that the turbine output ultimately matches the load. Primary side response is typical of other Pressurized Water Reactors.

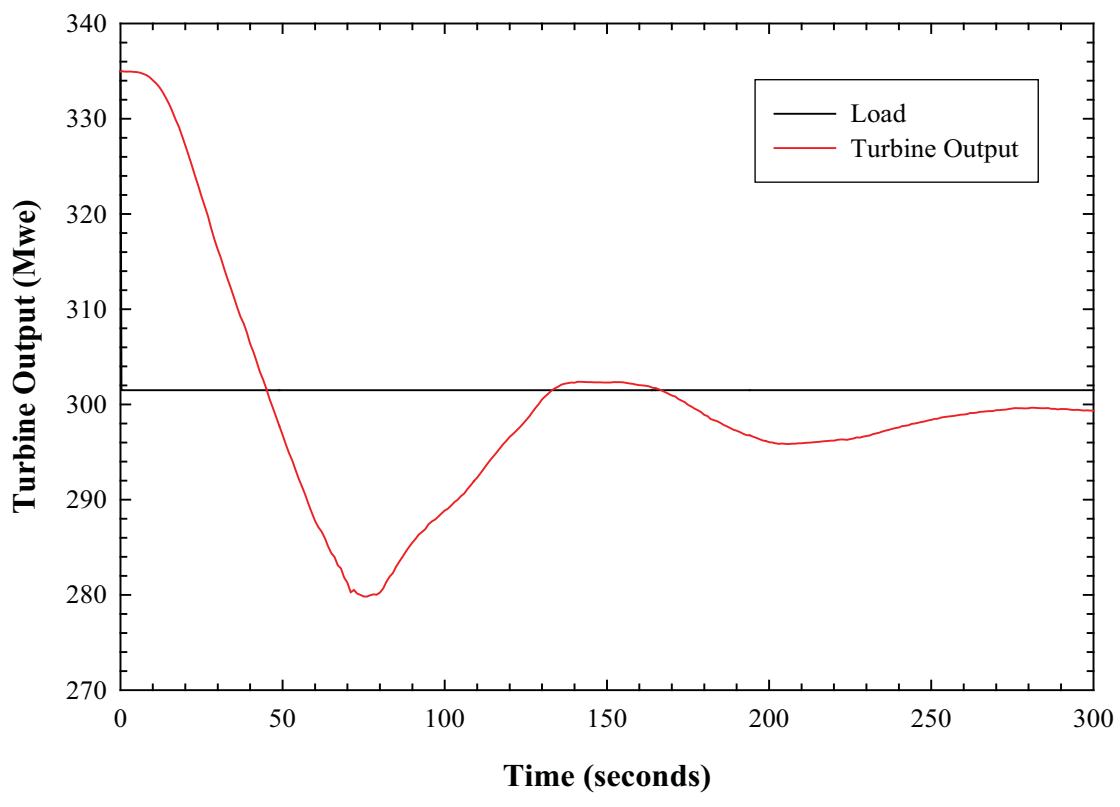

Figure 4. Turbine Output for 10\% Step Reduction in Load 


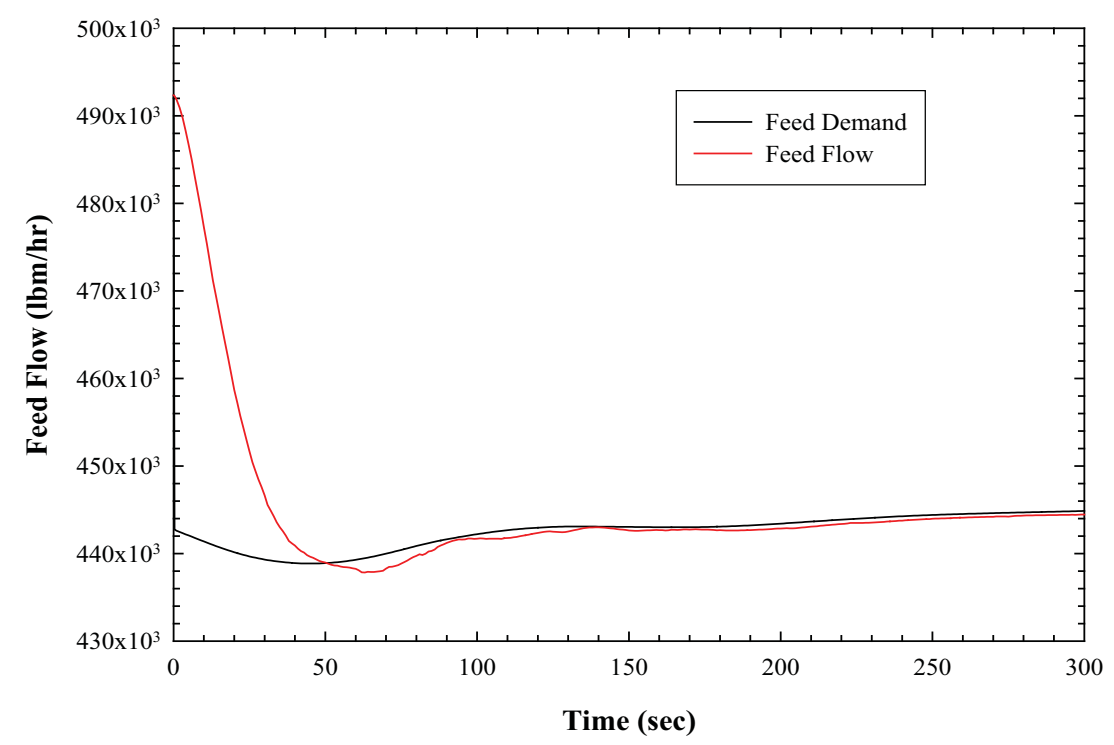

Figure 5. Feed Flow for a 10\% Step Reduction in Load

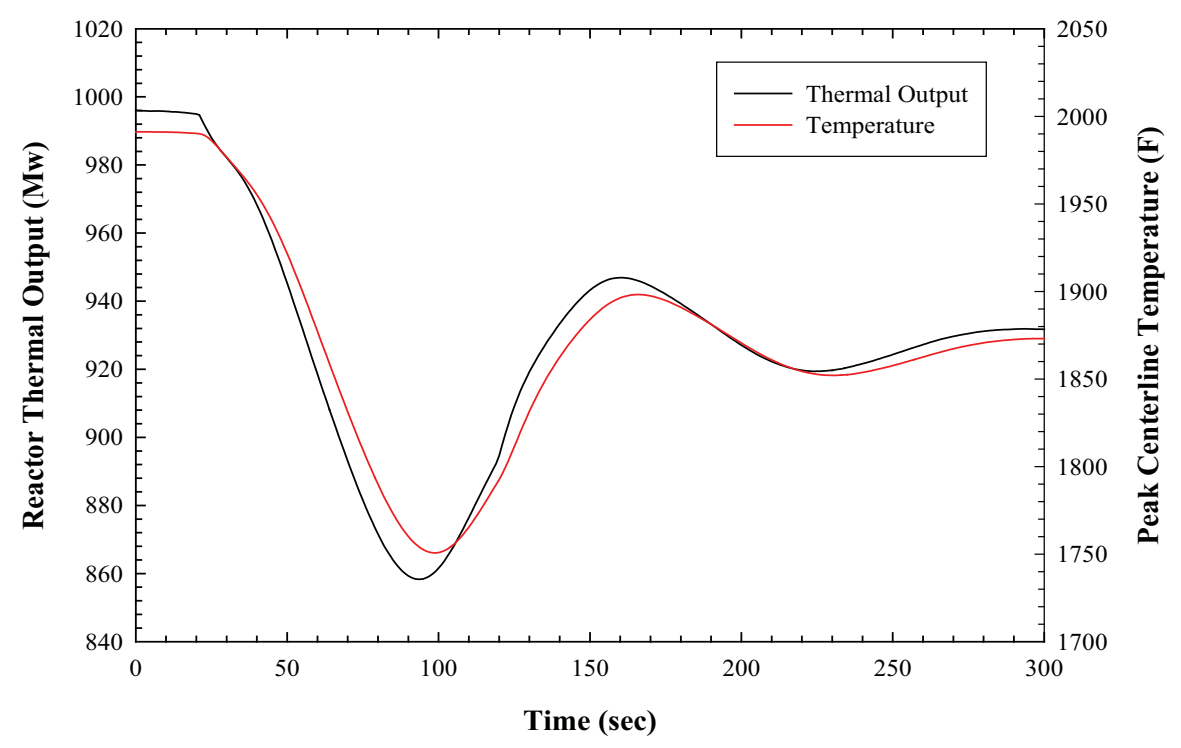

Figure 6. Reactor Thermal Output and Peak Centerline Temperature for 10\% Step Reduction 


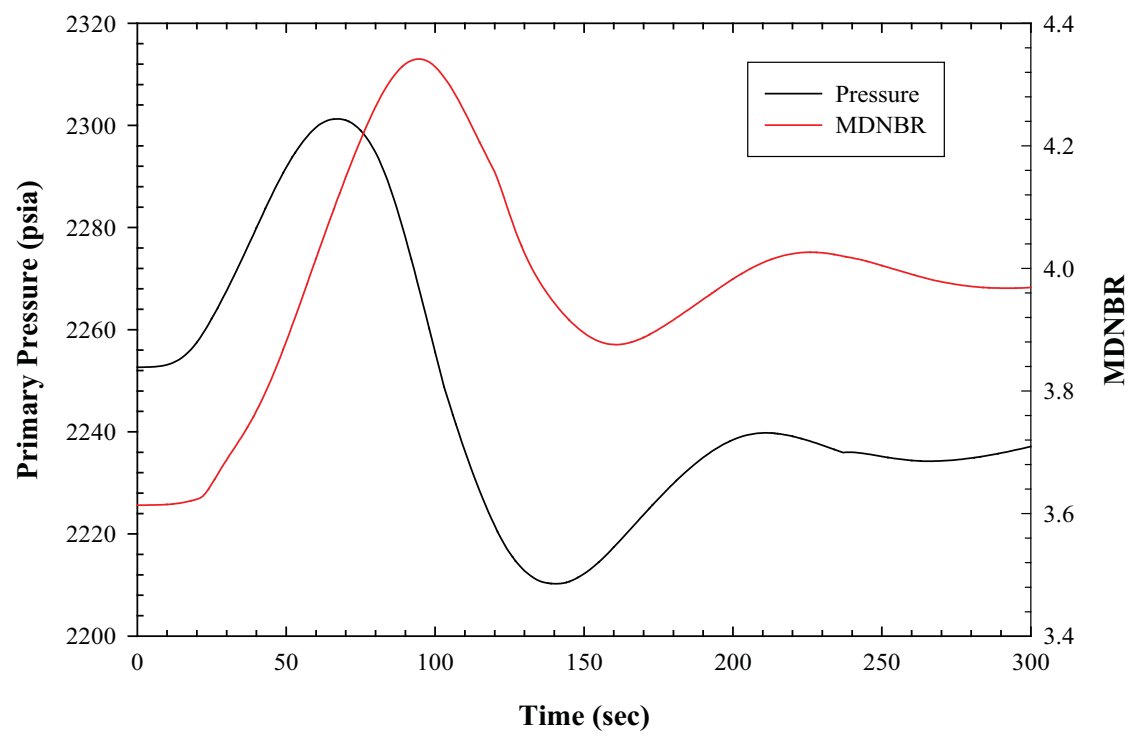

Figure 7. Primary System Pressure and Minimum DNB Ratio for 10\% Step Reduction in Load

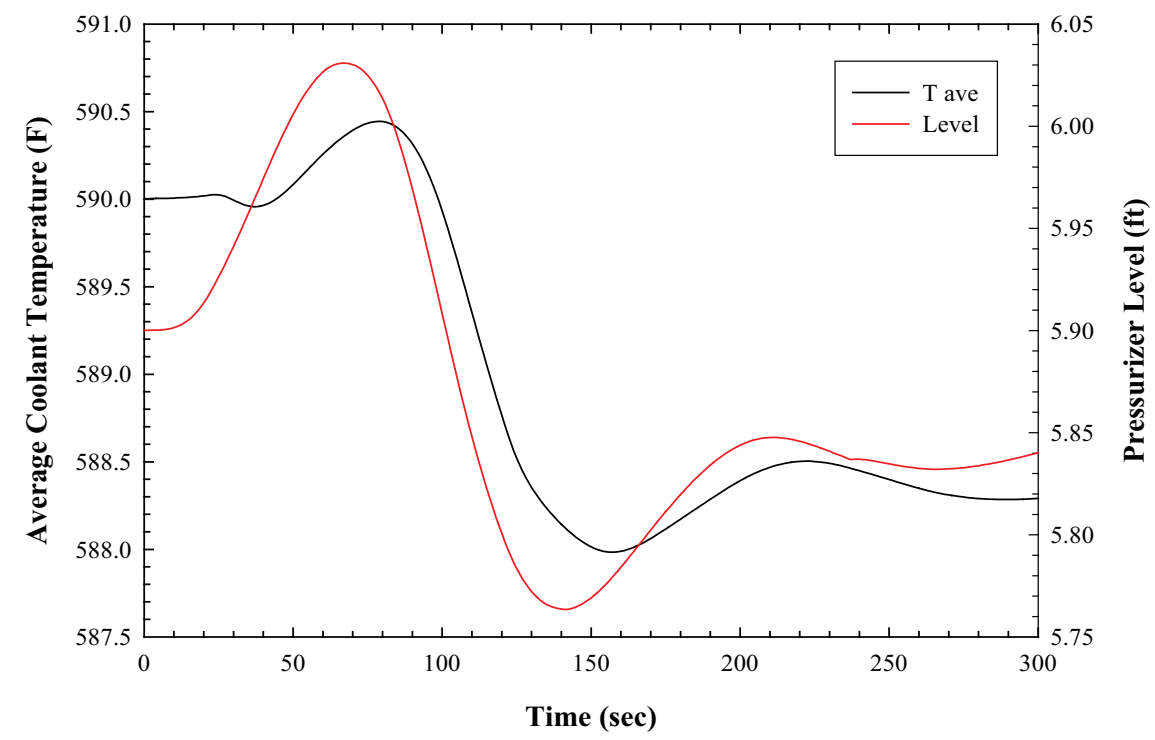

Figure 8. Average Primary Coolant Temperature and Pressurizer Level for 10\% Step Reduction in Load

Figures 9 - 13 illustrate a 10\% step reduction in load from $100 \%$ to $90 \%$ at time zero for the generic SMR model adopted for the NHES plant. The difference in the system response is due primarily to the significant difference in the thermal mass associated with the two systems and the associated response times. Optimization of the controller gains, valve characteristics and component sizes may eliminate some of these differences. 


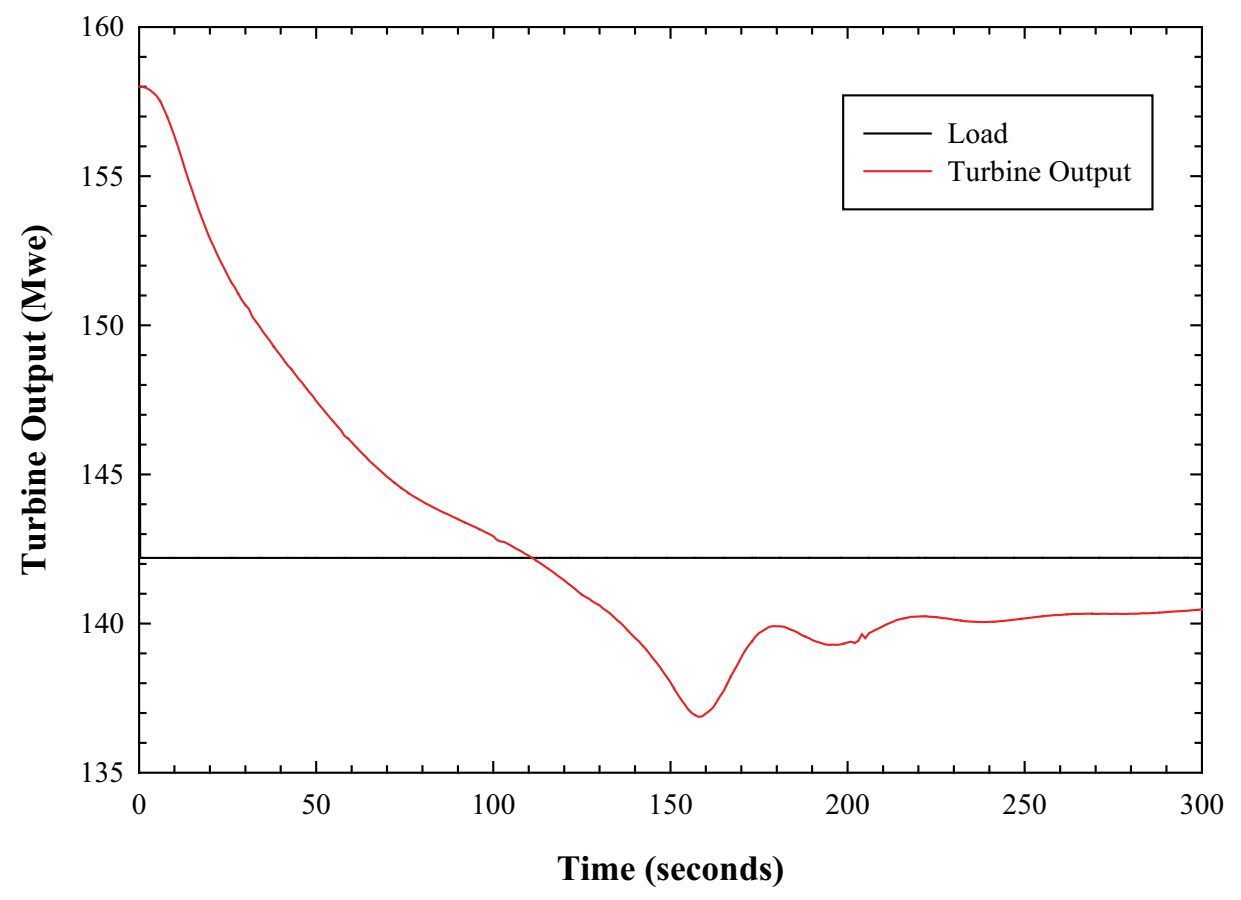

Figure 9. NHES Turbine Output for 10\% Step Reduction in Load

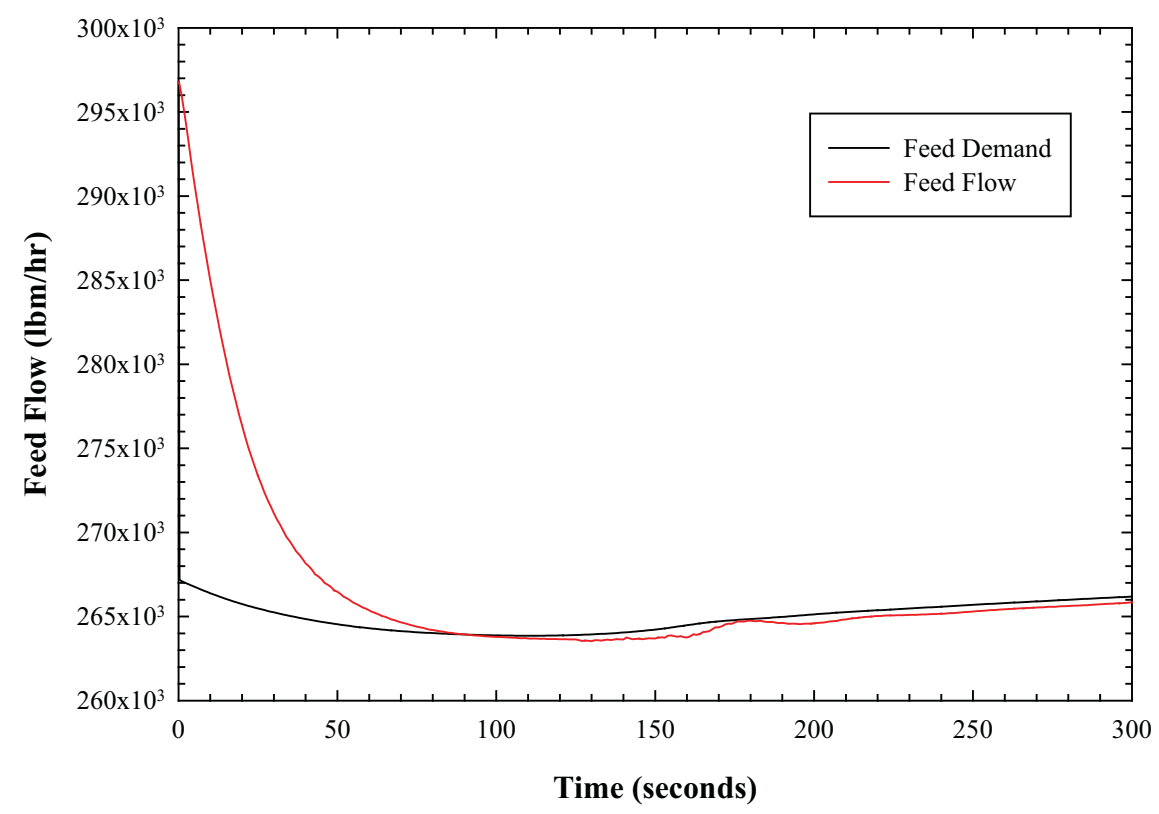

Figure 10. NHES Feed Flow for a 10\% Step Reduction in Load 


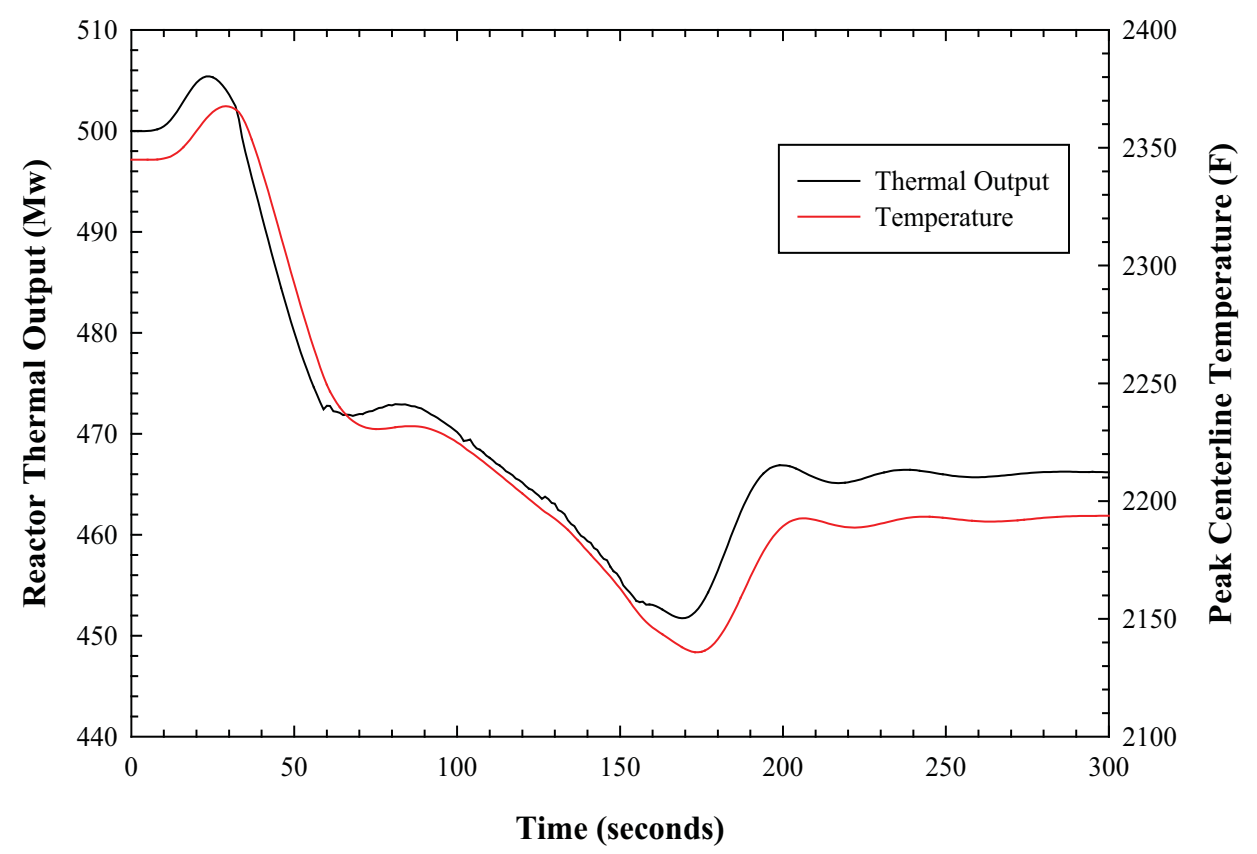

Figure 11. NHES Reactor Thermal Output and Peak Centerline Temperature for $10 \%$ Step Reduction in Load

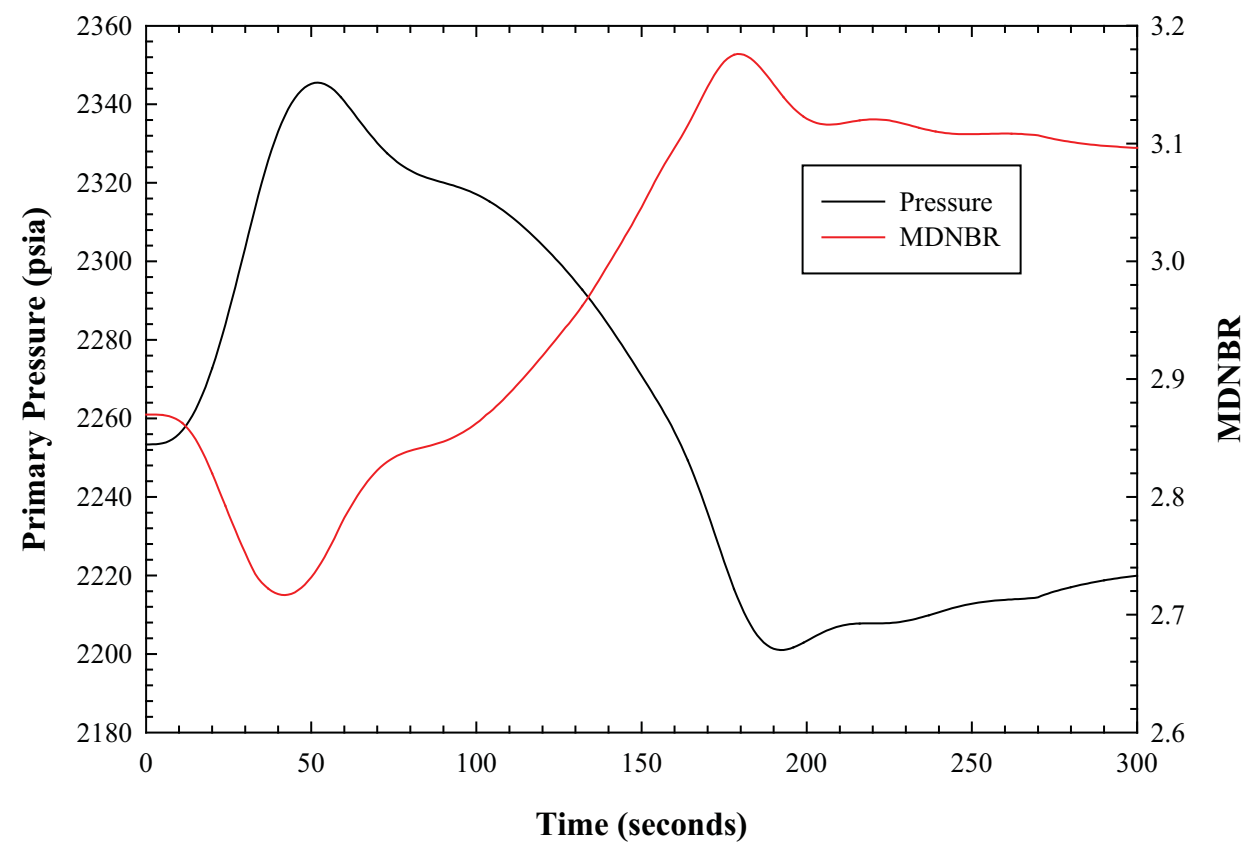

Figure 12. NHES Primary System Pressure and Minimum DNB Ratio for 10\% Step Reduction in Load 


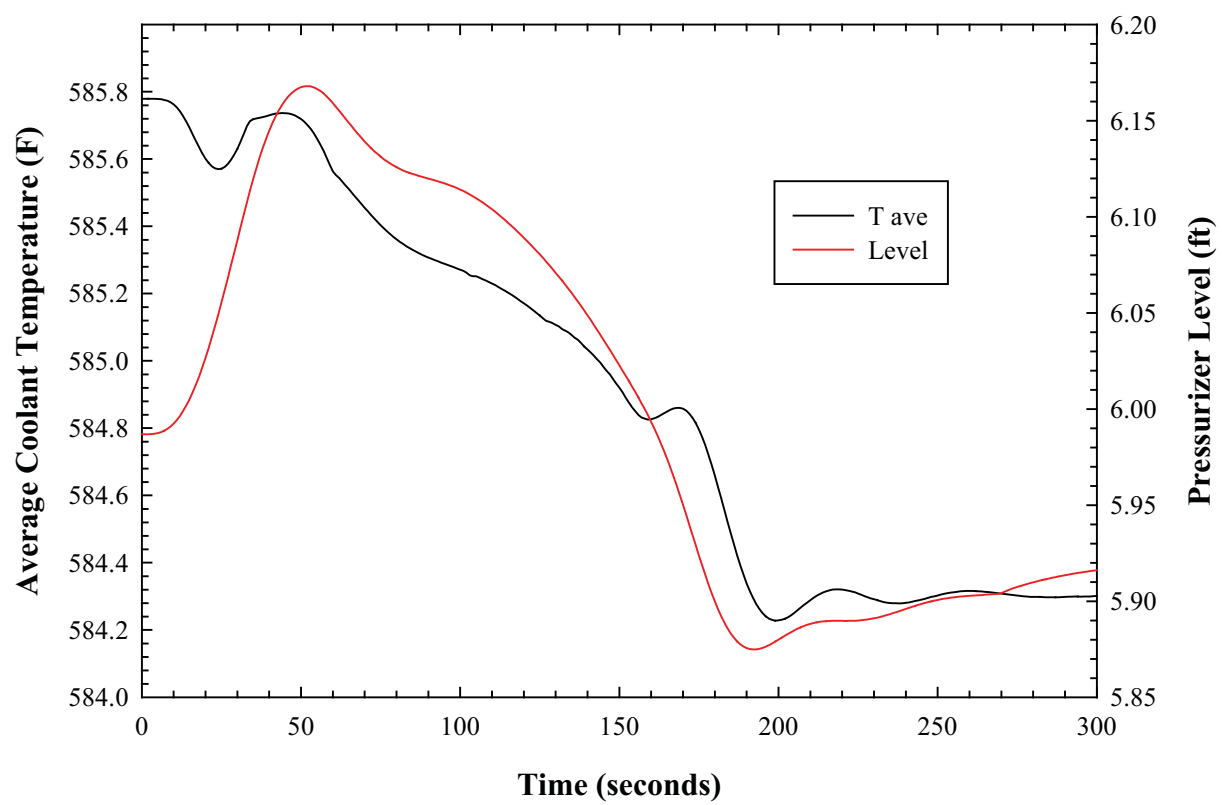

Figure 13. NHES Average Primary Coolant Temperature and Pressurizer Level for $10 \%$ Step Reduction in Load

\section{NHES SIMULATION COUPLING}

The full simulation of a nuclear hybrid energy system requires dynamic coupling of the reactor subsystem simulation with the remaining hybrid system components. The NHES research team at the INL has developed a dynamic simulation of a hybrid energy system that includes power conversion, renewable energy (wind in the current implementation), energy storage grid integration, and a process application that utilizes reactor-produced thermal energy. The non-reactor component and subsystem models are written in the Modelica language utilizing the Dymola software package; the full balance of plant simulation is then coupled to powerful mathematical solvers in MatLab. Coupling of the Fortran based reactor subsystem simulation with the balance of plant simulation is made at the steam generator, as shown by the red hash line in Figure 14 (note that the full detail of the balance of system components is not shown here for purposes of simplification). Because the reactor subsystem includes both the basic models and the solution of those models, this is referred to as a simulation rather than a model. Hence, a co-simulation approach is necessary to integrate the reactor simulation with the remainder of the hybrid energy system simulation. Several possible approaches to this integration were investigated and are summarized in the following subsections. 


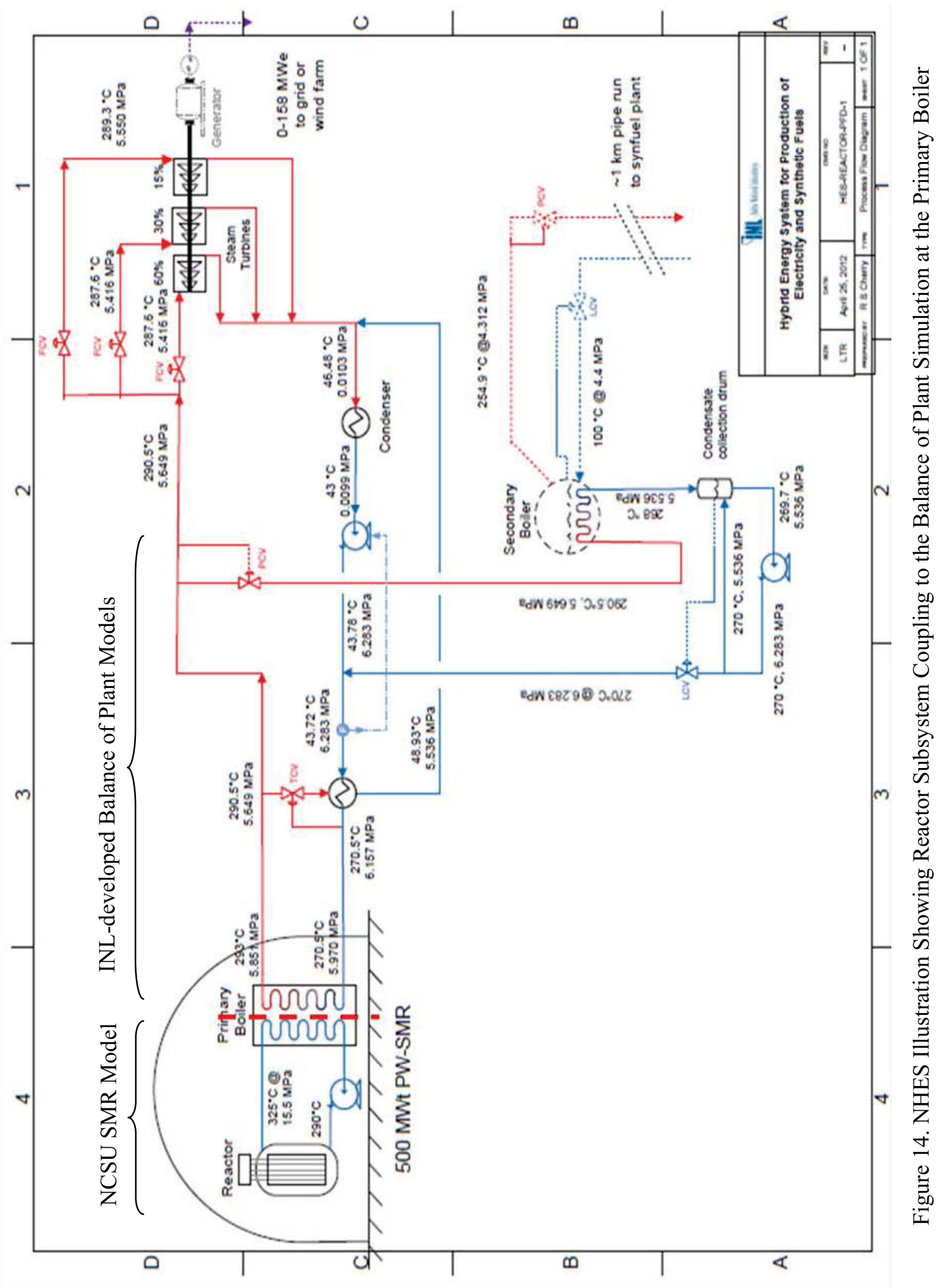




\subsection{Simulink}

The option of coupling the reactor subsystem to the balance of plant model using Simulink was attractive for several reasons, including the large number of libraries available natively to the MatLab/Simulink environment, the widespread use in research and publications, the ability to communicate with models built in a variety of languages, and the controls analysis tools in Simulink. Custom models are implemented in blocks called s-functions, which allow Simulink to dynamically call external compiled binaries of code written in languages such as $\mathrm{C}$ and Fortran.

The critical drawback of this option was the lack of a concrete and well-established approach for integrating the NHES model in its current form. The model-based approach of Simulink requires a statespace definition of the parameters of a block, including input, output, control input, state variables, and state variable time derivatives. This differs from the available Fortran based reactor simulation, which uses its own approaches for time integration in all its subsystems and communication between them. In this view, there were two ways to proceed with this option:

1. Rewrite the Fortran-based simulation to conform to the structure of common Simulink model blocks;

2. Use Simulink in a co-simulation framework.

The first option left little potential for reuse of existing code, and would not fit the objectives of the project. The second option lacked clear definition and sufficient precedent. Hence, the option described in 3.2 was identified as being more attractive to the current implementation.

\subsection{Building Controls Virtual Test Bed (BCVTB)}

The Building Controls Virtual Test Bed (BCVTB) is a software environment that is designed to facilitate co-simulation between a diverse set of programs. BCVTB uses a Java-based graphical user interface to visually build the high-level system and connects the different programs, allowing them to exchange data through the time integration. It is a modular, extensible, and open-source platform developed at Lawrence Berkeley National Laboratory.

Previous publications showed the software applied to building energy control systems ( $\operatorname{Tr}^{2} \mathrm{cka}$, Hensen, and Wetter 2009). The example of Fortran code implemented in this environment is the published two-body system of HVAC control. This case provides an example setup of a co-simulation as well as a block demonstrating a custom Fortran code. The interface and the Fortran block properties are shown in Figures 15 and 16. 


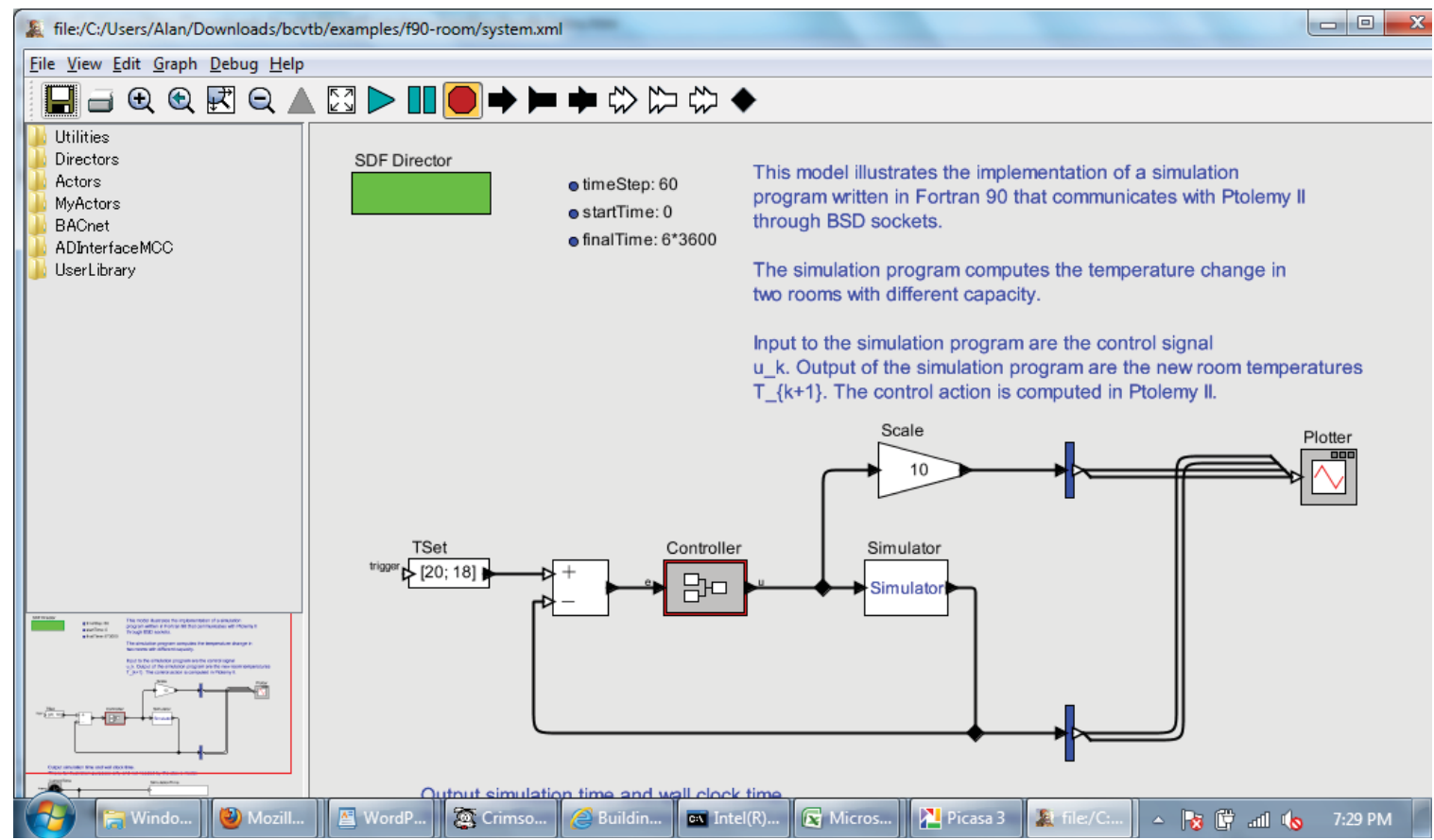

Figure 15. Two-body Co-simulation Example in BCVTB

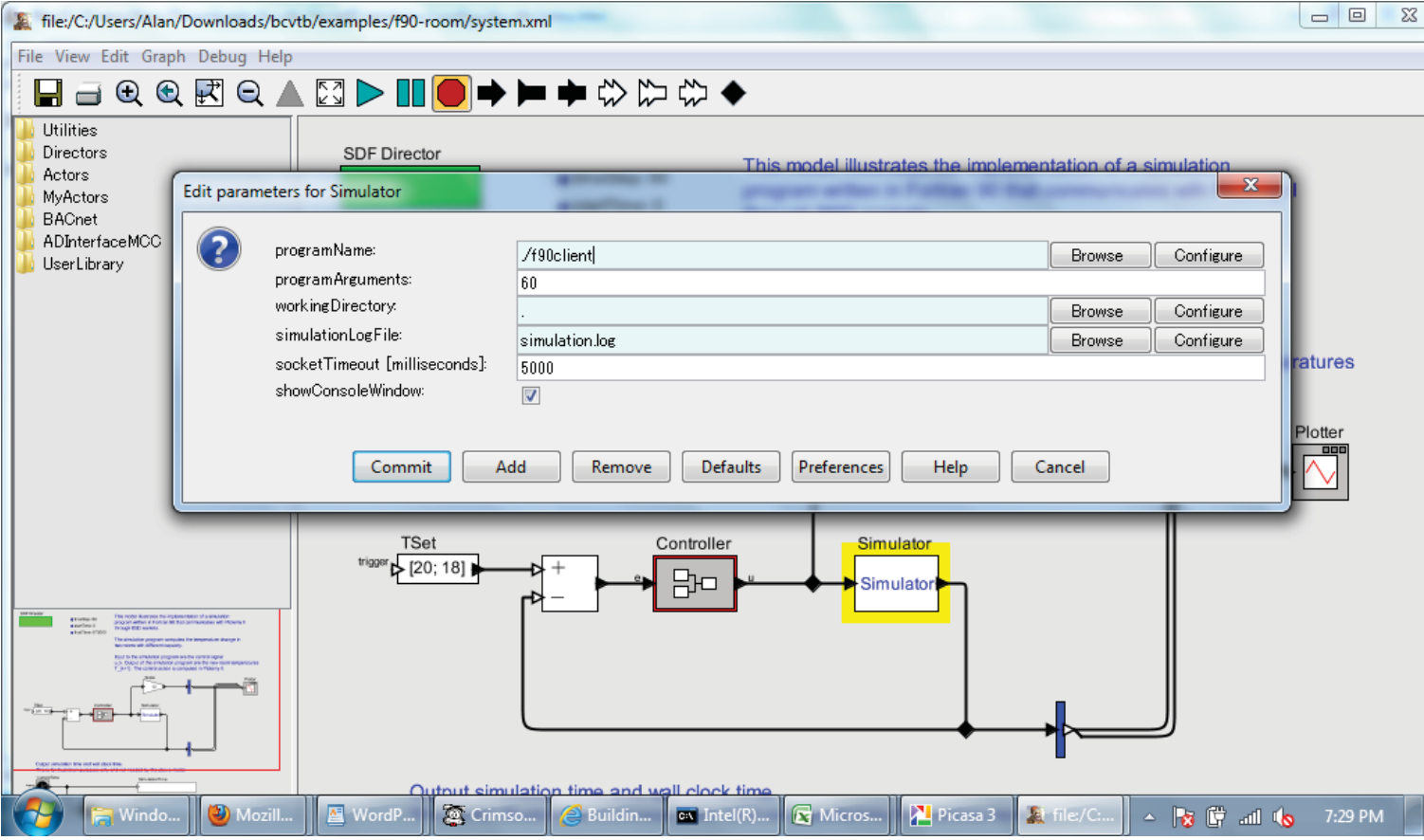

Figure 16. Custom Fortran Block Properties Simulation within the Example 


\section{STATUS OF INTEGRATED SYSTEM SIMULATION}

The Fortran simulation has been adapted to the BCVTB format, recompiled, and run within that software environment. Prior to establishing linkages between the reactor and balance of plant simulations the individual components were shown to be independently functional within the BCVTB environment. The BCVTB software was easily linked to the Matlab/Simulink and Modelica environments, with the primary challenge being to link the Fortran simulation to the other components within the BCVTB framework, facilitating data exchange.

Linking to the routines referenced by the interfaces in Fortran proved to be challenging. A very simple set of independent simulations were created in each environment (i.e. Fortran and Modelica) to allow the developers to become familiar with linking simulations in the BCVTB prior to attempting the more complex simulations. The various program versions used to accomplish a fully linked simulation include Java JDK version JDK6u35, Intel Fortran Compiler 11.1.072 and Visual Studio 2010 Professional. Several trial simulations have been run using different Fortran source files. Accomplishing a co-simulation with the more complex hybrid energy system components should now be possible but had not yet been demonstrated at the time of this report.

\section{CONCLUSIONS AND FUTURE EFFORTS}

Linking the reactor and balance of plant subsystems in a nuclear hybrid energy system environment proved to be more challenging than was expected. The reactor subsystem simulation developed by NCSU has been successfully modified to represent a "generic" integral PWR similar to various SMR designed currently being proposed. The current simulation includes a complex helical coil steam generator, but could be modified to a straight tube design with little effort. The operation of neutronic and thermal hydraulic simulation has been validated as an independent simulation as described in this document. The Fortran and Modelica / Dymola subsystem simulations could not easily be linked using Simulink, as originally planned. Hence, an alternate approach to linking the subsystem simulations was sought; the Java-based BCVTB software environment developed by Lawrence Berkeley National Laboratory was identified as a solution that would establish a dynamic co-simulation environment for the NHES simulation. Simplified sample simulations have been successfully linked with BCVTB; full linkage of the reactor subsystem and balance of plant can now be accomplished. Once fully operational, the coupled simulation will be used to:

1. Identify key requirements and performance measures for a nuclear power source that would be coupled to a multi-input multi-output hybrid energy system;

2. Define desirable operating parameters for candidate reactor technologies for hybrid systems;

3. Identify key challenges to system thermal hydraulics, reactor control and overall system safety that result from operation with load following or load partitioning; and

4. Perform initial analyses of potential operating regimes for the NHES.

System analysis results will aid NHES development through the characterization of system sensitivity to changes at various points in the integrated system. Sensitivity analysis results will allow researchers to hone in on requirements for reactor design and operating parameters and will highlight key needs for system development and testing. 


\section{REFERENCES}

A. S. Rominger and J. M. Doster, "Fast Valving for Small and Medium Sized Nuclear Reactors", Proceedings of the $7^{\text {th }}$ International Topical Meeting on Nuclear Plant Instrumentation, Control and Human-Machine Interface Technologies (NPIC\&HMIT 2010), Las Vegas, Nevada, November, 2010.

M. Trcka, J. L. M. Hensen, and M. Wetter, "Co-simulation of innovative integrated HVAC systems in buildings," Journal of Building Performance Simulation, vol. 2, no. 3, 2009. 